\title{
Multi Criteria Decision Making (MCDM) based preference elicitation framework for life insurance recommendation system
}

\author{
Asha Rani $^{1}$, Kavita Taneja ${ }^{2}$, Harmunish Taneja ${ }^{3}$ \\ ${ }^{1}$ GGN Khalsa College, Ludhiana, INDIA \\ ${ }^{2}$ Panjab University, Chandigarh, INDIA \\ ${ }^{3}$ DAV College, Sec. 10, Chandigarh, INDIA \\ asharana20@gmail.com ${ }^{1}$
}

Article History: Received: 10 November 2020; Revised: 12 January 2021; Accepted: 27 January 2021; Published online: 05 April 2021

\begin{abstract}
The global life insurance industry has shown a phenomenal growth in number of companies, insurance products and their users. The digital revolution has played a pivotal role in the field of insurance too. Increased numbers of companies and insurance plans have increased the complexities and time involved in selection of appropriate policies. At present, major share of policy selling goes to the agents which may be biased and time consuming. The web aggregators too have failed to provide customized and personalized suggestions. Major portion of population still finds the selection of best insurance plan unfriendly and tedious. This huge volume of data requires intelligent system to facilitate efficient and effective retrieval, processing and management of the data from multiple dimensions. This research paper proposes a framework to provide a personalized life insurance recommender system using TOPSIS method of multi-criteria decision making. Point allocation method along with TOPSIS provides preference elicitation and list of recommended policies ranked according to closeness coefficients. Sensitivity analysis in the paper shows the effect of changing the policy features' preferences (criteria weights) on the final recommended products. The proposed framework helps in achieving computational excellence for efficient decision making with reduced complexity
\end{abstract}

Keywords: Multi criteria decision making, TOPSIS, Web Aggregators, Insurance plans

\section{Introduction}

Insurance policy is a contract in which insurer provide the assurance of financial support and security to the insured and his/her dependents in return of some assessed payment. Insurance can broadly classified as general insurance and life insurance. Life insurance further have sub- categories as Term (pure risk cover), Unit linked (insurance + investment benefits), Endowment (insurance cover + savings), Money back (insurance cover with periodic returns), Whole life (insurance for lifetime coverage), Retirement (financial independence post retirement) and Child's Plans (corpus for child's education/marriage etc.). Life insurance has achieved tremendous success in all other insurance policy types as no one wants to get family suffered due to financial crisis. The life insurance industry is experiencing a huge content being induced from various insurance companies and their customers in the form of number of companies, plans, features and customers. This exponential growth of digital data over the internet has created requirement of techniques that can manage and organize data efficiently which could result in effective information retrieval on web (Dhuria, S. et al.2016)). Information retrieval should cater the heterogeneity and dynamic nature of data (Suri, P. \& Taneja, H., 2010). Life Insurance Recommender Systems (LIRS) extricate the customers from confusion, agent's commissions and personal biases and wrong selection of products which in turn results in suggestions based on personalized requirements.

\subsection{Recommender Systems}

Recommender system (RS) is a subclass of information filtering system that provide the "rating" or "preference" a user would give to an item and suggests products and services accordingly (Isinkaye et al., 2015). RS find exhaustive usage in the field of music, movies, restaurants, e commerce, online games, books, research articles, wide range of services etc. Broadly, RS techniques can be classified in: Content based, Collaborative filtering based, Knowledge Based and Hybrid techniques. These traditional RS use explicit data (ratings) and implicit data $(\operatorname{logs})$ to predict items for the users. Traditional RS could not be employed in insurance sector directly because of the dissimilarities in terms of item complexities, domain size, customer expertise, demographic features, user constraints and interaction frequency (Rokach et al., 2013). Insurance recommender system (IRS) should exhibit following characteristics:

1. Sensitivity: IRS should be sensitive enough towards the preference change. Preferences change with time, age, requirement and income. One can opt for different policies for the multi facet requirements such as periodic returns, tax benefit, investments, life security, retirement plans etc 
2. Independency: IRS should not be dependent on the user ratings because insurance domain lacks frequent visits of users.

3. Critical in nature: Insurance selection is a critical decision in one's life as insurance products are need based products not taste based. IRS helps in selecting a life insurance policy which is very important in one's life as compared to any e-commerce products like movies, services, food, songs, books etc.

IRS provides adequate recommendations on the basis of customer's interaction history, demographics, preferences, similarity in customers' profile or similarity in the content of various products.

\subsection{MCDM}

Multi-Criteria Decision Making (MCDM) are a part of operations research which are concerned with designing of decision making methodologies comprising of computational and mathematical tools for evaluation of criteria performance for various alternatives (Mardani et al. (2015), Kaur and Kadam (2017, 2019)). MCDM have played remarkable role in economy, insurance, portfolio selection, healthcare, medicine etc. It can be considered as a decision-making (DM) tool for real world problems based on both quantitative/qualitative factors in risky/certain/uncertain environments so as to find a suitable choice/plan/course of action among the available alternatives (Raju, K. S.; Kumar, N. D., 2013). DM is based on preferences of criterion (criterion weights) and optimal choice among alternatives. Objective measurements and value judgements are integrated in MCDM to make subjectivity explicit. MCDM have five components:

1. Goal (answer to the problem)

2. Preferences (opinions of the decision maker)

3. Alternatives (options of decisions)

4. Weight assignment (evaluation criteria)

5. Outcomes (alternative and interest combination)

Due to high complexity and limited interaction frequency in life insurance products, people lack expertise to choose an appropriate policy from different alternatives (options of policies) incorporating multiple criteria (policy features and constraints). MCDM methods can be utilized efficiently in recommending insurance products. Very few methods such as Analytic Hierarchical Process (AHP), Grey Relational Analysis (GRA), Multi Attribute Utility theory (MAUT) etc. of MCDM are utilized in LIRS. There is a huge variety in MCDM which can be explored for its applicability in RS.

\section{Related Work}

Most of the researches done in the field of IRS are concentrated for recommending products of a particular company and hence based on collaborative filtering techniques for policy recommendations. These techniques recommend the taste based products not need based and hence lack efficiency in recommending products with multiple features from multiple companies with different preferences of users. (Rokach et al., 2013) proposed the RS for matching the policy riders to the base policy (life and annuity insurance) for clients in the call centres by using collaborative filtering. A. Abbas et. al. (Abbas et al., 2015) worked on health insurance plans and proposed MAUT based recommendation system involving coverage and cost criteria for recommending appropriate plan. (Xu et al., 2017) proposed vehicle insurance policies recommendation model using clustering analysis, Neural Network and Apriori algorithm. (Qazi et al., 2017) worked on providing a recommendation system for agents to assist them in recommending auto, life, property and umbrella policies using Bayesian Networks (BN). (Kanchinadam et al., 2019) deployed their model for agents of American Family Insurance, USA to recommend cross-sell and up-sell products. A.B. Davale et. al. (Devale, 2012) investigates the applicability of data mining techniques for pattern and knowledge discovery in insurance business. ( A. Gupta et. al. A. Gupta and A. Jain. 2013) discusses a life insurance web recommender system using web data mining techniques for the insurance seekers (customers) as well as life insurance representative (agents) to select a suitable life insurance plan using Apriori Association Rule Algorithm. (Mitra et al., 2014) shows the concept of a hybrid recommendation model using similarity matrix for policy recommendations and collaborative filtering for rider recommendations. (Hinduja \& Pandey, 2018) illustrates recommendation system for life insurance plans using utility based MCDM. Preference elicitation and policy matching are performed using Intuitionistic fuzzy sets (IFS) and Grey Relation Analysis (GRA) respectively. The author demonstrated the work using an empirical study. MCDM are found to be efficient enough in the field where there are multiple criteria and alternatives. So, a unified RS can be achieved by using MCDM. In India, the standardized research in life insurance recommendation sector is found to be limited. Major studies provide empirical results with limited validation and testing. This paper proposes a framework for IRS using MCDM. 


\section{Proposed Framework}

The proposed framework is divided into four phases. First phase is domain modeling, which comprises of creating a knowledge repository of background information of different policies. In second phase certain inputs are taken from users, third phase matches the inputs of users with the constraints of policies and forms clusters. Fourth phase is taking the specifications of preferences for different policy features and fifth phase delivers a recommended and ranked list of policies.

\subsection{Phase I- Data Modeling:}

In this phase policy data model is created which is divided into two sub divisions- policy constraints and policy features.

\section{Policy Constraints:}

There are some features of policies which are mandatory to be matched with the customer's demographic specifications. We identified following policy constraints from literature review:

1. Entry age: Each policy has a min. entry age and max entry age. The customer's age must lie between the two. Age is directly proportional to the premium amount, which means younger the age, lesser will be the premium.

2. Term: The period of validity of a policy is known as term. Every policy has a specified min and max term. The customer can choose the term as per requirement. Longer the term lesser will be the premium.

3. Sum Assured: The amount which is to be paid by the insurance company on death/survival of the customer. Every policy has a min sum assured but no limit for max sum assured for most of the policies. Higher the sum assured chosen by customer higher will be the amount of premium to be paid.

4. Maturity Age: It is the age at which policy of customer get matured. Major policies have max. maturity age and few have min. maturity age.

Maturity Age $>=$ Customer's Age + term

\section{Policy Features:}

Dutta (Dutta et al., 2010) identified 9 key parameters of Life Insurance Policies. The study considers 10 key features for evaluating criteria of insurance policies and finds the weight of each criteria to find overall weightage:

1. Low premium

2. Flexibility in payment structure

3. Tax benefits

4. Benefits on death

5. Benefits on survival

6. Policy Loan

7 Bonus

8 Riders availability

9 Claim Settlement ratio

10 Rebate on premium

\subsection{Phase II- Data Input Phase:}

A recommendation system is said to be accurate if the suggestions delivered are appropriate which satisfy user's requirement. This accuracy can be attained with exclusive knowledge of user's choices and preferences. This phase is dedicated to extract user's information in two parts: firstly, demographic features (Age, Income, Sum assured and Term) are obtained from the users and compared with the policy constraints for the applicability of policy to the user. In the second phase, the preference modeling for the policy features is done using MCDM. 


\subsection{Phase III- Cluster Formation:}

The policy model contains different types of policies of different companies (Figure 1). The companies are represented with $\mathrm{C} 1, \mathrm{C} 2, \ldots \mathrm{Cn}$ while the Endowment plan (E), Child plan (D), Term plan (T), Pension plan (P), Retirement plan (R), Unit linked plan (U) and Money back plan (M) for the nth company are EnCn, $\mathrm{DnCn}$, $\mathrm{TnCn}, \mathrm{PnCn}, \mathrm{RnCn}, \mathrm{UnCn}$ and $\mathrm{MnCn}$ respectively.

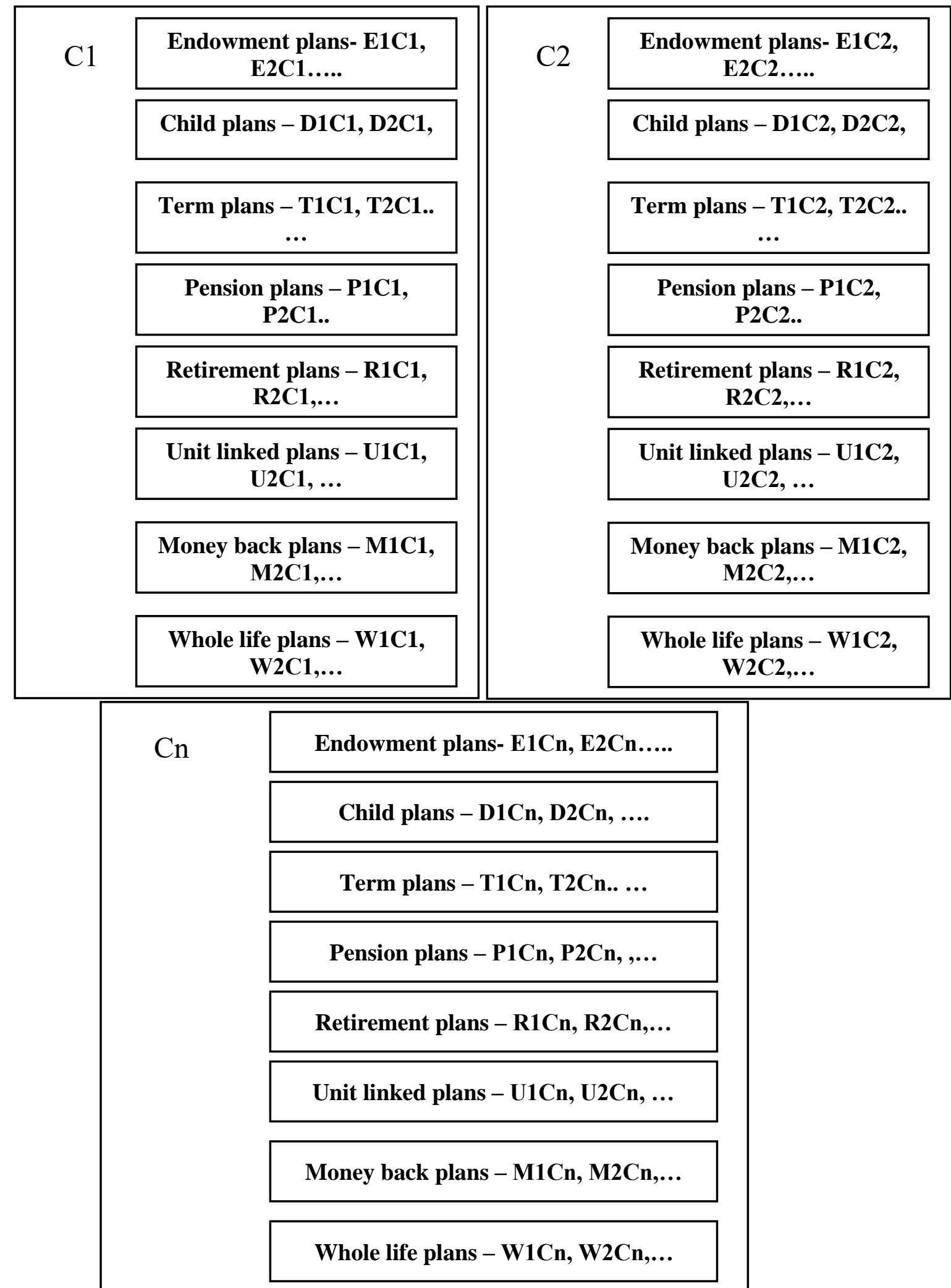

Figure 1. Different policies of different companies $(\mathrm{C} 1, \mathrm{C} 2, \mathrm{C} 3, \ldots \ldots \mathrm{Cn})$ 
User's demographic specifications are matched with the policy constraints and results are generated in the form of 7 clusters of different types of policies. Each cluster contains the matched policy of a particular category of different companies. (Figure 2).

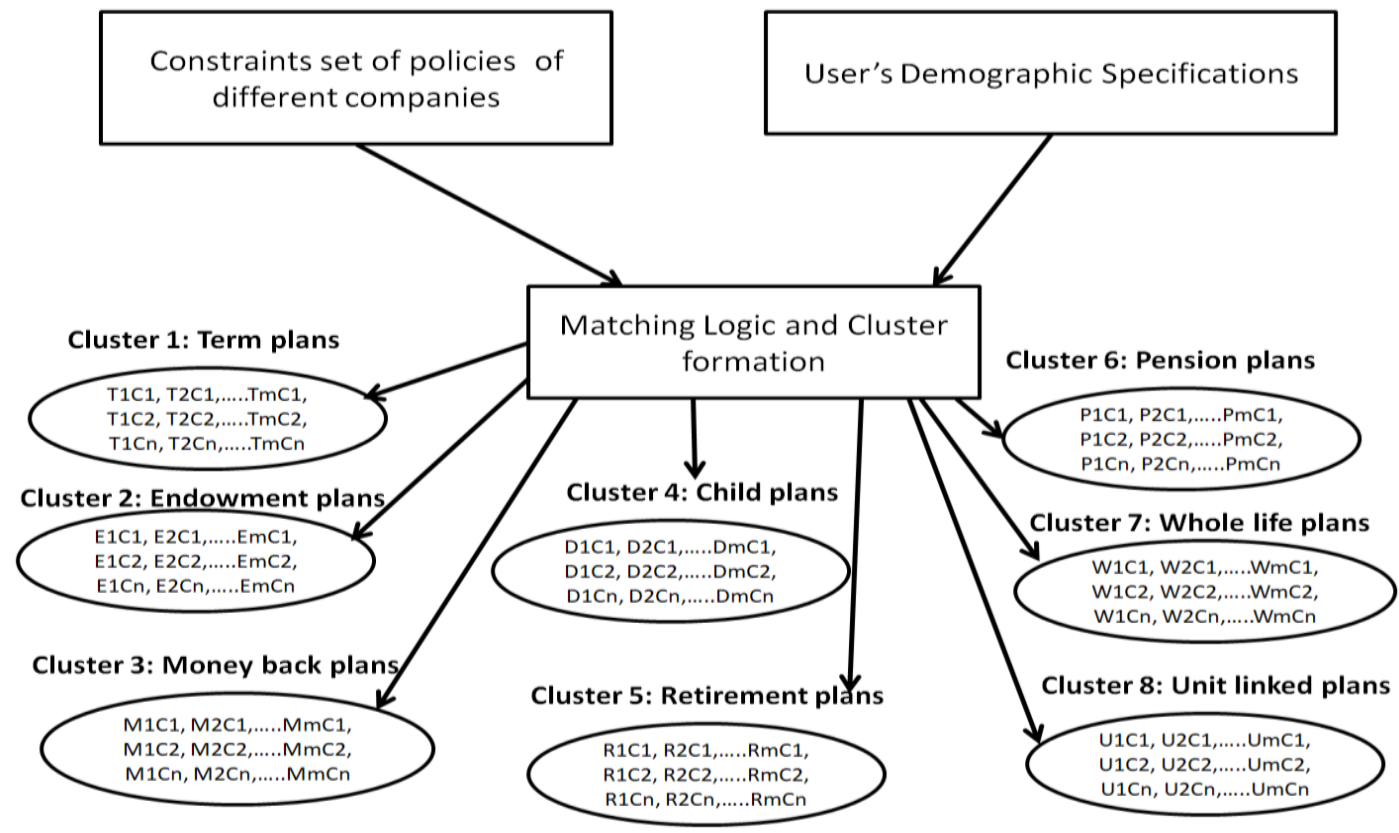

Figure 2. Cluster Formation on the basis of matched demographic features

\subsection{Phase IV- Preferences Specification}

The proposed framework advocates the use of MCDM for preference specification. MCDM have a large variety of methods. The major challenge is in the assessment and modeling of preferences for decision making (Siskos, 1982). Roy (Roy, 1990) suggested a possible way to represent the preferences in terms of four binary relations:

1. $\mathbf{a} \mathbf{I} \mathbf{b}: \mathrm{a}$ is indifferent to $\mathrm{b}$

2. $\mathrm{a} \mathbf{P} \mathrm{b}: \mathrm{a}$ is strictly preferred to $\mathrm{b}$

3. $\mathrm{a} \mathbf{Q} \mathrm{b}: \mathrm{a}$ is weakly preferred to $\mathrm{b}$

4. a $\mathbf{R} \mathbf{b}$ : not sure whether $\mathrm{a} \mathbf{P}$ b or $\mathrm{b} \mathbf{P}$ a

On the basis of likelihood of exchange of preferences between criteria, MCDM methods can be (G. Colson, et al., 1989):

1. Compensatory: This approach is based on absolute compensation means high performance on one criterion can balance the weak performance of some other criterion. E.g. Weighted Sum method.

2. Non-compensatory: no compensation is undertaken among the different criteria. E. g. Lexicographic method

3. Partially compensatory: This approach involves partial compensation between the various criteria. Majority of MCDM methods comes in this category. Eg. MAUT, AHP, SMART, TOPSIS etc.

In MCDM, each criterion is assigned some weight and weight assignment is an important as well as key problem in MCDM. Several methods of weight assignments have been proposed in literature (Aldian, 2005; Diakoulaki et al., 1995; Ginevicius \& Podvezko, 2004; Pamučar et al., 2018). Weighted Sum Method (WSM) is probably the earliest and widely used. In 1977, Saaty (Saaty, 1977) proposed Analytic Hierarchy Process (AHP) which received immense popularity. Several modifications of AHP e.g. Fuzzy AHP are more prevalent than the original. Other commonly used methods are ELECTRE, TOPSIS, MAUT, etc. In MCDM, weight assigned to the criteria comprises of the qualitative and quantitative data both so as to obtain better and accurate decisions. Determination of weights can be divided into 3 categories (Ginevicius \& Podvezko, 2004): Subjective weighting methods ( Point allocation, Direct rating, Ranking method, Pairwise comparison, Ratio method), Objective weighing method (Entropy method, Mean weight, Standard deviation, Statistical variance procedure, Ideal point method) and Hybrid weighing methods (Multiplication synthesis, Additive synthesis, Optimal weighting based 
on sum of squares, Optimal weighting based on relational coefficient of graduation). Figure 3 explains the process of preference specification. The preferences show user's individual requirement and presumptions from the policy. His/her preferences are converted into weights using suitable weighting methods the overall weight of preferences is calculated which is required to compare with the policies by using matching techniques.

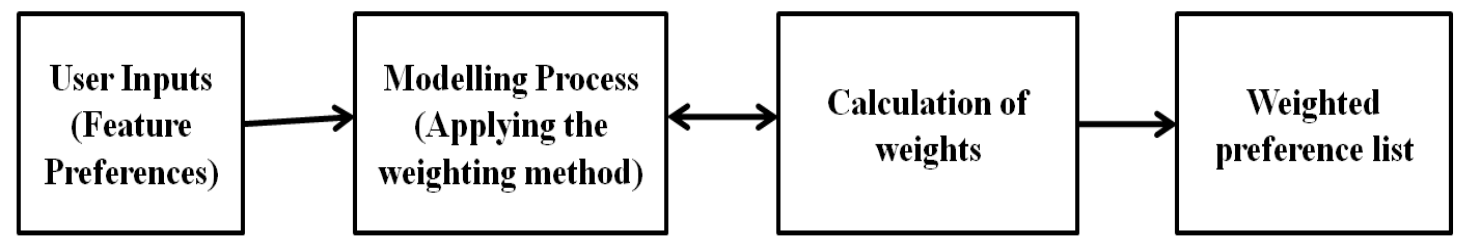

Figure 3. Process of Preference Specification

\subsection{Phase V- Recommendation Phase:}

The weighted preference s obtained from the previous phase are used to calculate the average weight of each cluster and compared with user's preferences weight. The cluster which matches the most is selected and then in the cluster, policies are ranked as per the individual score of preference specification.

The overall proposed framework is shown in figure 5.

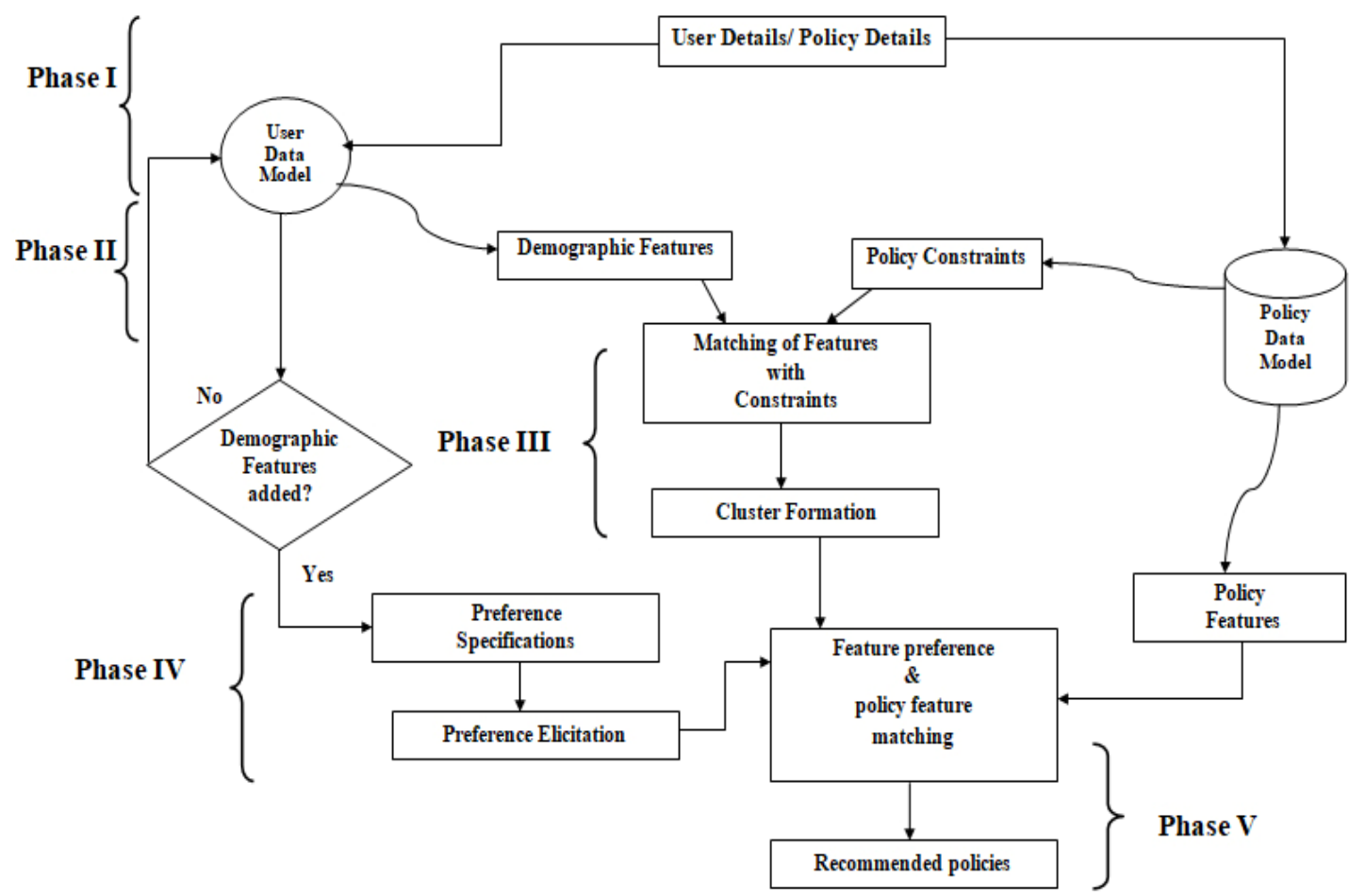

Figure 4. The proposed framework

\section{Empirical Case Study}

In this section, we demonstrate an example for the illustration purpose. For simplified illustration, we have taken only 40 life insurance products that belong to different categories (e.g. term plans, endowment plan, money-back Plan, children's Plan) of two companies (LIC and SBI Life).

The first step is to obtain user's demographic features as in Table 1. These values are compared with the policy constraints already stored in the database.

Table 1. Demographic features of the user

Feature Input value

Age 45 


\begin{tabular}{ll}
\hline Annual Income & 500000 \\
\hline Sum Assured & 600000 \\
\hline
\end{tabular}

The policies constraints of 10 policies match with the demographic features mentioned in Table 1 as shown in Figure 5.

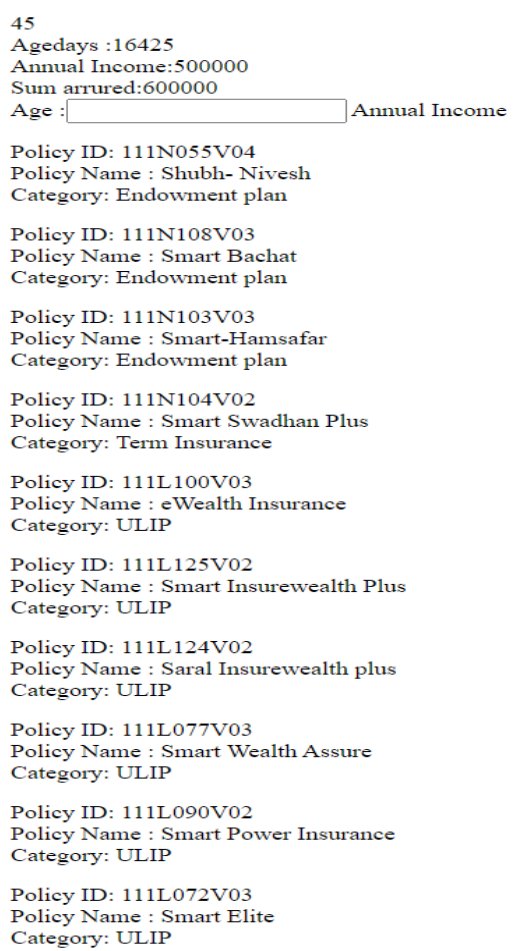

Figure 5. Results obtained after comparing the demographic features with policy constraints

The score of a policy over quantitative criteria is simply estimated by normalizing the quantitative benefits it produces for its customer and already stored in the knowledge repository. Each criterion is given a maximum score of 10 producing a total score of 100 as shown in table 2

Table 2. Score of each criterion for various life insurance plans for which the user is eligible

\begin{tabular}{|c|c|c|c|c|c|c|c|c|c|c|c|}
\hline$\underset{\dot{Z}}{\dot{\Omega}}$ & 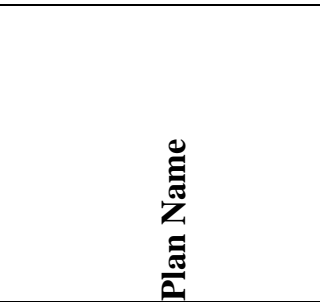 & 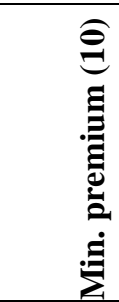 & 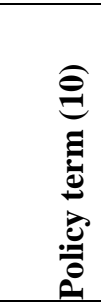 & 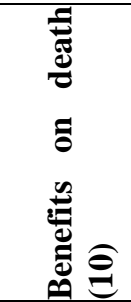 & 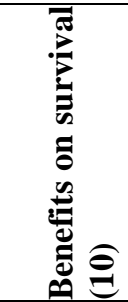 & 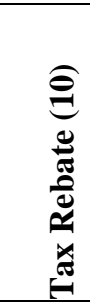 & 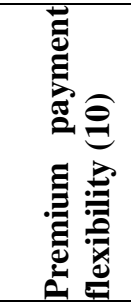 & 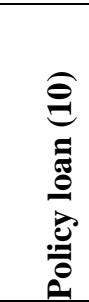 & 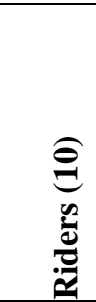 & 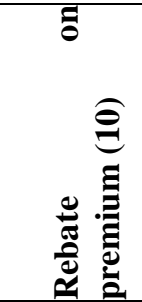 & 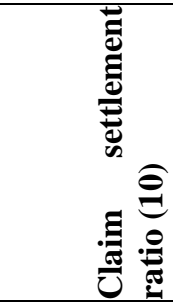 \\
\hline 1 & eWealth Insurance & 2 & 2 & 4 & 2 & 10 & 4 & 0 & 0 & 0 & 10 \\
\hline 2 & Smart Swadhan Plus & 10 & 2 & 4 & 2 & 0 & 10 & 0 & 0 & 0 & 10 \\
\hline 3 & Shubh Nivesh & 10 & 4 & 4 & 2 & 10 & 10 & 9 & 6 & 0 & 10 \\
\hline 4 & Smart Bachat & 10 & 4 & 4 & 2 & 10 & 8 & 0 & 0 & 0 & 10 \\
\hline 5 & Smart Humsafar & 10 & 2 & 4 & 2 & 10 & 8 & 9 & 2 & 10 & 10 \\
\hline 6 & $\begin{array}{l}\text { Smart Insure Wealtl } \\
\text { Plus }\end{array}$ & $\mathrm{h}_{2}$ & 2 & 4 & 2 & 10 & 2 & 0 & 2 & 0 & 10 \\
\hline 7 & Smart Wealth Assure & & 2 & 4 & 2 & 10 & 2 & 0 & 2 & 0 & 10 \\
\hline 8 & $\begin{array}{l}\text { Smart } \\
\text { Insurance }\end{array}$ & $\mathrm{r}_{2}$ & 2 & 4 & 2 & 10 & 8 & 0 & 0 & 10 & 10 \\
\hline 9 & Smart Elite & 2 & 4 & 4 & 2 & 10 & 8 & 0 & 0 & 0 & 10 \\
\hline 10 & $\begin{array}{l}\text { Saral Insure Wealtl } \\
\text { plus }\end{array}$ & $\mathrm{h}_{2}$ & 2 & 4 & 2 & 10 & 2 & 0 & 0 & 0 & 10 \\
\hline
\end{tabular}


Next step is to take user's preferences for different criteria of the plans. Point allocation method is used for taking the relative criteria importance (preference elicitation) and user is asked to distribute a score of 100 among different criteria. User's preferences are shown in table 3.

Table 3. User preference for policy features

\begin{tabular}{|c|c|c|c|c|c|c|c|c|c|}
\hline 㤩葛 & 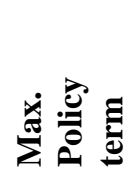 & 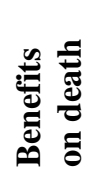 & 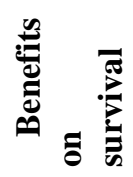 & 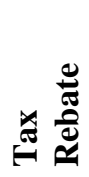 & 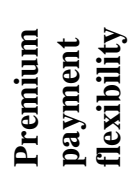 & 总 & $\frac{\pi}{2}$ & 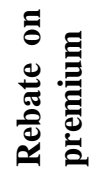 & 䲩离 \\
\hline 20 & 10 & 20 & 10 & 5 & 10 & 5 & 5 & 5 & 10 \\
\hline
\end{tabular}

The proposed framework then evaluates all ten policies over each feature for the preferences provided by the user. The paper uses one of the known classical MCDM approaches, TOPSIS (Hung \& Chen, 2009) for finding the most suitable policy. TOPSIS has good computational efficiency and efficient in representing each alternative in mathematical form besides maintaining its simplicity (Hung \& Chen, 2009). This method works on the principle that best alternative should have the shortest distance from positive ideal solution and farthest distance from the negative ideal solution. Firstly, the decision matrix is constructed and weights of different criteria on the basis of preferences specified by the user are determined. In second step, normalized decision matrix is constructed which is multiplied by respective criteria weights to obtain weighted normalized matrix in third step. In fourth step, positive ideal solution $\mathrm{A}^{+}$and negative ideal solution $\mathrm{A}^{-}$are determined which helps in calculating the distance of each alternative from positive ideal solution $\left(\mathrm{d}_{i}^{+}\right)$and negative ideal solution $\left(\mathrm{d}_{i}{ }^{-}\right)$. In last step the closeness coefficient $\left(\mathrm{C}_{\mathrm{i}}\right)$ is determined and the alternative whose $\mathrm{C}_{\mathrm{i}}$ is close to 1 is selected. Table 4 shows the values of $\left(\mathrm{d}_{\mathrm{i}}^{+}\right),\left(\mathrm{d}_{\mathrm{i}}^{-}\right)$and $\left(\mathrm{C}_{\mathrm{i}}\right)$ for the example taken.

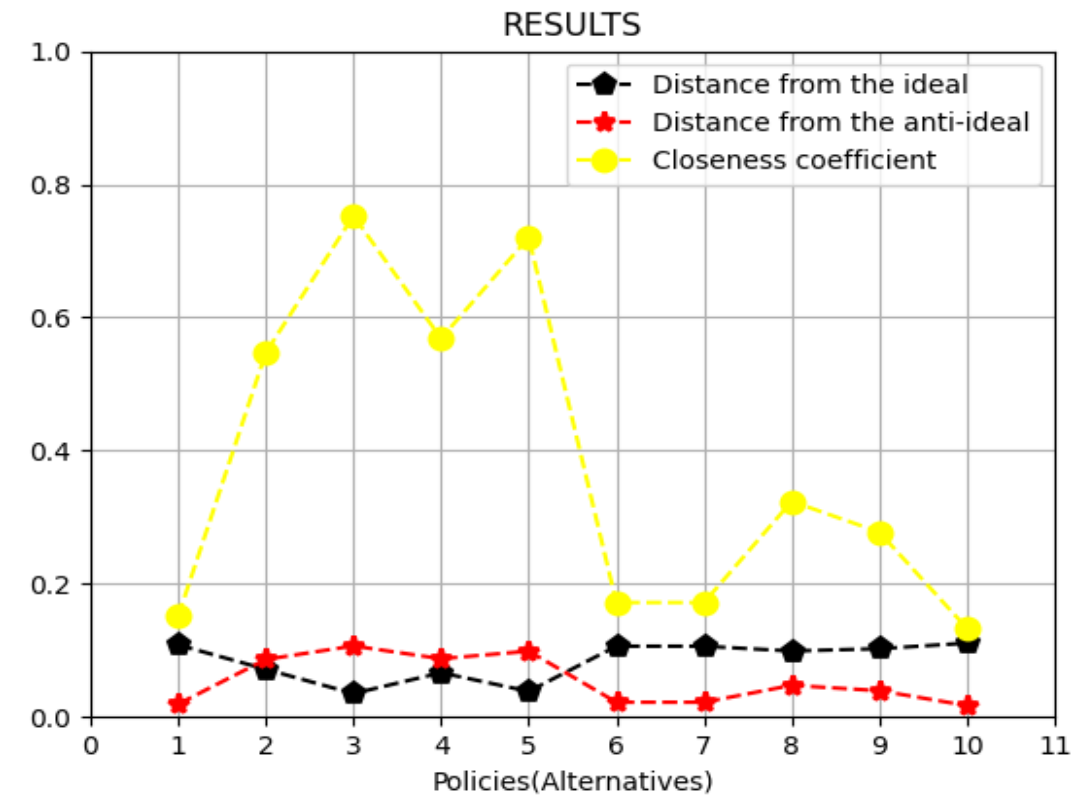

Figure 6. Ideal solution, anti-ideal solution, and closeness coefficient for the filtered policies

Table 4. Ideal solution, anti-ideal solution, and Closeness Coefficient for the filtered policies

\begin{tabular}{llll}
\hline Policy S. No. & $\mathbf{d}_{\mathbf{i}}^{+}$ & $\mathbf{d}_{\mathbf{i}}^{+}$ & $\mathbf{C}_{\mathbf{i}}$ \\
\hline 1 & 0.10814805 & 0.01923538 & 0.15100382 \\
\hline 2 & 0.07153321 & 0.08633076 & 0.54686804 \\
\hline 3 & 0.035 & 0.10651291 & 0.75267274 \\
\hline 4 & 0.06632496 & 0.0873556 & 0.56842322 \\
\hline 5 & 0.03834058 & 0.09873196 & 0.72028986 \\
\hline 6 & 0.10617438 & 0.02202272 & 0.17178794 \\
\hline 8 & 0.10617438 & 0.02202272 & 0.17178794 \\
\hline 9 & 0.09892927 & 0.04736032 & 0.32374362 \\
\hline
\end{tabular}




\begin{tabular}{llll}
\hline 10 & 0.11081967 & 0.017 & 0.13299987 \\
\hline
\end{tabular}

\section{Results and Discussion}

From the table 4, we get a ranked list of alternatives as policy no. 3, policy no.5, policy no. 4, policy no. 2 , policy no. 8 , policy no. 9 , policy no. 6 , policy no.7, policy no. 1 and policy no. 10 . In order to examine whether the changes in preferences of criteria (criteria weight) specified by the user influence the priorities of alternatives, sensitive analysis was carried out. The user with same demographic features as mentioned in Table 1 now gives different preferences to criteria (Table5).

Table 5. Changed Criteria Weights

\begin{tabular}{|c|c|c|c|c|c|c|c|c|c|}
\hline 㤩总 & 离离 & 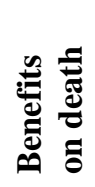 & 苞 & 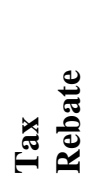 & 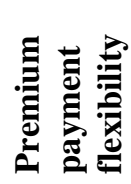 & 矛 & $\frac{n}{20}$ & 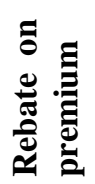 & 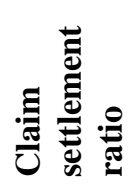 \\
\hline 5 & 10 & 5 & 5 & 10 & 20 & 5 & 5 & 30 & 5 \\
\hline
\end{tabular}

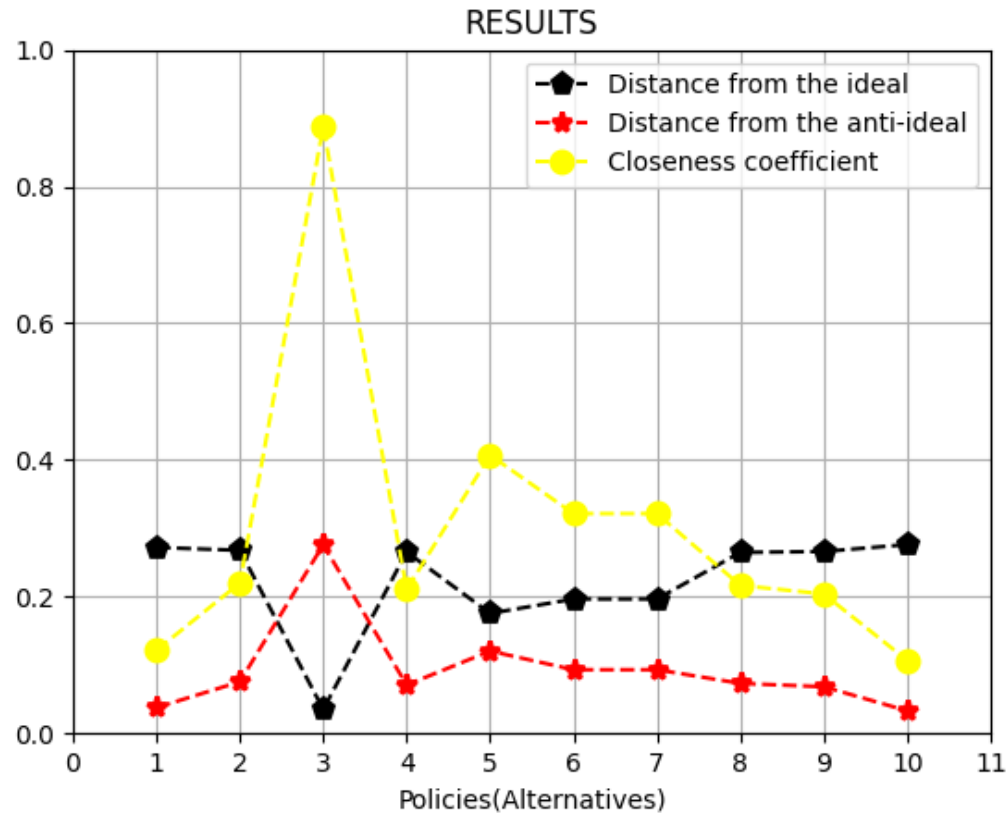

Figure 7. Ideal solution, anti-ideal solution, and closeness coefficient for the changed criteria weight scenario

Table 6. Closeness Coefficient For The Changed Criteria Weight Scenario

\begin{tabular}{ll}
\hline Plan S. No. & Closeness Coefficient $\left(\mathbf{C}_{\mathbf{i}}\right)$ \\
\hline 1 & $\mathbf{0 . 1 2 1 4 3 2 0 4}$ \\
\hline 2 & $\mathbf{0 . 2 1 9 8 2 8 3 3}$ \\
\hline 3 & $\mathbf{0 . 8 8 7 4 3 1 6 1}$ \\
\hline 4 & $\mathbf{0 . 2 1 0 5 2 0 1 2}$ \\
\hline 5 & $\mathbf{0 . 4 0 6 9 4 7 7 6}$ \\
\hline 6 & $\mathbf{0 . 3 2 1 3 9 7 1 7}$ \\
\hline 7 & $\mathbf{0 . 3 2 1 3 9 7 1 7}$ \\
\hline 8 & $\mathbf{0 . 2 1 6 3 5 9 8 5}$ \\
\hline 9 & $\mathbf{0 . 2 0 3 9 4 9 5 5}$ \\
\hline 10 & $\mathbf{0 . 1 0 6 7 3 7 9 4}$ \\
\hline
\end{tabular}

The Table 6 shows the closeness coefficient score of each plan and now the ranked list of alternatives is policy no.3, policy no. 5 , policy no. 6 , policy no.7, policy no.2, policy no. 8 , policy no.9, policy no. 1 and policy no.10. The method TOPSIS is found to be sensitive towards the changes in criteria weights as the rank of policy no $4\left(\mathrm{C}_{\mathrm{i}^{-}} \mathbf{\mathbf { 0 . 5 6 8 4 2 3 2 2 }}\right)$ and policy no $2\left(C_{i^{-}} \mathbf{0 . 5 4 6 8 6 8 0 4}\right)$ are replaced by policy no $6\left(C_{i^{-}} \mathbf{- 0 . 3 2 1 3 9 7 1 7}\right)$ and policy no $7\left(C_{i}-\mathbf{0 . 3 2 1 3 9 7 1 7}\right)$ respectively. Buying an insurance plan is a contextual decision as the same person can opt for different plans as per the requirements. 


\section{Conclusion and Future Work}

Life insurance has now become a crucial product for future financial planning as well as the contingency management. Selecting an appropriate product is very complex and time consuming process. Also, the maximum dependency lies on insurance advisors/agents which incorporate their personal biases while recommending. We have demonstrated the framework by using point allocation method (Table 3) for taking the user's preferences for policy features (criteria weights) and TOPSIS method for recommending an appropriate policy based on the personal specifications of the user. A sensitivity analysis demonstrates change in criteria weights changes the overall priorities of the policies.

Our future work will be concentrated on developing a life insurance recommender system which will recommend life insurance products based on user's financial state, future and current needs.

\section{References}

1. Abbas, A., Bilal, K., Zhang, L., \& Khan, S. U. (2015). A cloud based health insurance plan recommendation system: A user centered approach. Future Generation Computer Systems, 43-44, 99-109. https://doi.org/10.1016/j.future.2014.08.010

2. A. Gupta and A. Jain. (2013). Life insurance recommender system based on association rule mining and dual clustering method for solving cold-start problem. International Journal of Advanced Research in Computer Science and Software Engineering, 3(10), pp. 951-954.

3. Aldian, A. (2005). a Consistent Method To Determine Flexible Criteria Weights for Multicriteria Transport Project Evaluation in Developing Countries. Journal of the Eastern Asia Society for Transportation Studies, 6, 3948-3963.

4. Devale, A. B. (2012). Applications of D Ata M Ining T Echniques in. 2(4), 31-40.

5. Diakoulaki, D., Mavrotas, G., \& Papayannakis, L. (1995). Determining objective weights in multiple criteria problems: The critic method. Computers and Operations Research, 22(7), 763 770. https://doi.org/10.1016/0305-0548(94)00059-H

6. Dutta, G., Basu, S., \& John, J. (2010). Development of utility function for life insurance buyers in the Indian market. Journal of the Operational Research Society, 61(4), 585-593. https://doi.org/10.1057/jors.2009.26

7. Ginevicius, R., \& Podvezko, V. (2004). Objective and Subjective Approaches to Determining the Criterion Weight in Multicriteria Models. Proceeding of International Conference RelStat 2004, 1, 133-139.

8. G. Colson, C. De Bruyn.(1989).Models and Methods in Multiple Criteria Decision Making. Pergamon Press, Oxford.

9. Hinduja, A., \& Pandey, M. (2018). An Intuitionistic Fuzzy AHP based Multi Criteria Recommender System for Life Insurance Products. International Journal of Advanced Studies in Computer Science and Engineering, 7(1), https://doi.org/https://www.researchgate.net/publication/323143943

10. Hung, C., \& Chen, L. (2009). A Fuzzy TOPSIS Decision Making Model with Entropy Weight under Intuitionistic Fuzzy Environment. International MultiConference of Engineers and Computer Scientists 2009, I, 18-21.

11. Isinkaye, F. O., Folajimi, Y. O., \& Ojokoh, B. A. (2015). Recommendation systems: Principles, methods and evaluation. Egyptian Informatics Journal, 16(3), 261-273. https://doi.org/10.1016/j.eij.2015.06.005

12. Kanchinadam, T., Qazi, M., Bockhorst, J., Morell, M. Y., Meissner, K., \& Fung, G. (2019). Using Discriminative Graphical Models for Insurance Recommender Systems. Proceedings - 17th IEEE International Conference on Machine Learning and Applications, ICMLA 2018, 5, 421-428. https://doi.org/10.1109/ICMLA.2018.00069

13. Kaur M., Kadam S., (2017) Discovery of resources using MADM approaches for parallel and distributed computing, Engineering Science and Technology, an International Journal, Vol. 20, Issue 3, 1013-1024. https://doi.org/10.1016/j.jestch.2017.04.006.

14. Kaur M., Kadam S., (2019) Discovery of resources over Cloud using MADM approaches, International Journal for Engineering Modelling, 32 (2) (2019) 1013-1024.

15. Mardani, A., Jusoh, A., Nor, K. M. D., Khalifah, Z., Zakwan, N., \& Valipour, A. (2015). Multiple criteria decision-making techniques and their applications - A review of the literature from 2000 to 2014. Economic Research-Ekonomska Istrazivanja , 28(1), 516-571. https://doi.org/10.1080/1331677X.2015.1075139

16. Mitra, S., Chaudhari, N., \& Patwardhan, B. (2014). Leveraging Hybrid Recommendation System 
In Insurance Domain. International Journal Of Engineering And Computer Science, 3(10), 89888992.

17. Pamučar, D., Stević, Ž., \& Sremac, S. (2018). A new model for determiningweight coefficients of criteria in MCDM models: Full Consistency Method (FUCOM). Symmetry, 10(9), 1-22. https://doi.org/10.3390/sym10090393

18. Pushpa Suri, Harmunish Taneja. (2010). Object Oriented Information Computing over WWW. International Journal of Computer Science Issue. 7.

19. Qazi, M., Fung, G. M., Meissner, K. J., \& Fontes, E. R. (2017). An insurance recommendation system using Bayesian networks. RecSys 2017 - Proceedings of the 11th ACM Conference on Recommender Systems, 274-278. https://doi.org/10.1145/3109859.3109907

20. Raju, K. S.; Kumar, D. M., \& 2013. (n.d.). Multicriterion_Analysis_in_Engineering_a.pdf (Kindle edi). PHI Learning Private Limited.

21. Rokach, L., Shani, G., Shapira, B., Chapnik, E., \& Siboni, G. (2013). Recommending insurance riders. Proceedings of the ACM Symposium on Applied Computing, 253-260. https://doi.org/10.1145/2480362.2480417

22. Roy, B. (1990). The outranking approach. Theory and Decision, 31, 49 73.

23. Saaty, T. L. (1977). A scaling method for priorities in hierarchical structures. Journal of Mathematical Psychology, 15(3), 234-281. https://doi.org/10.1016/0022-2496(77) 90033-5

24. S. Dhuria, H. Taneja and K. Taneja. (2016). NLP and ontology based clustering - An integrated approach for optimal information extraction from social web. 3rd International Conference on Computing for Sustainable Global Development (INDIACom), New Delhi, pp. 1765-1770.

25. Siskos, J. (1982). A way to deal with fuzzy preferences in multi-criteria decision problems. European Journal of Operational Research, 10(3), 314-324. https://doi.org/10.1016/03772217(82)90230-2

26. Xu, W., Wang, J., Zhao, Z., Sun, C., \& Ma, J. (2017). A Novel Intelligence Recommendation Model for Insurance Products with Consumer Segmentation. Journal of Systems Science and Information, 2(1), 16-28. https://doi.org/10.1515/jssi-2014-0016 